\title{
An investigation on the effects of personal characteristics on creativity and innovation
}

\author{
Gholamreza Memarzadeh Tehran $^{\mathrm{a}^{*}}$ and Fatemeh Khaledi ${ }^{\mathrm{b}}$
}

${ }^{a}$ Associate \& Faculty Member, Department of Public Management, Science and Research branch, Islamic Azad university (IAU), Tehran, Iran ${ }^{b}$ M.Sc. Student, Department of Public Management, Science and Research branch, Islamic Azad University (IAU), Tehran, Iran

\section{H R O N I C L E}

\section{Article history:}

Received January 4, 2014

Accepted 1 June 2014

Available online

June 52014

Keywords:

Creativity and Innovation

Personal characteristics

Municipality

\begin{abstract}
A B S T R A C T
This paper examines the effects of big Five factors including openness, conscientiousness, extraversion, agreeableness, and neuroticism on creativity and innovation among selected employees of municipality in city of Tehran, Iran. The proposed study uses a standard questionnaire developed by Costa and McCrae (1980) [Costa, P. T., \& McCrae, R. R. (1980). Influence of extraversion and neuroticism on subjective well-being: happy and unhappy people. Journal of Personality and Social Psychology, 38(4), 668.] to measure the effects of five personality characteristics. In addition, the study has adopted a questionnaire developed by Torrents et al. (2010) [Torrents, C., Castaner, M., DINUŠOVÁ, M., \& Anguera, M. T. (2010). Discovering new ways of moving: Observational analysis of motor creativity while dancing contact improvisation and the influence of the partner. The Journal of Creative Behavior, 44(1), 53-69.] for measuring creativity. Using a simple regression analysis, the study has detected negative and meaningful relationship between neuroticism and creativity and innovation $(\beta=-$ 0.229 , t-value $=-3.196$ ), a positive and meaningful relationship between extraversion and creativity and innovation $(\beta=0.209, \mathrm{t}$-value $=3.204)$ and finally a positive and meaningful relationship between openness and creativity and innovation $(\beta=0.225$, t-value $=3.717)$. However, the study did not confirm any relationship between agreeableness as well as conscientiousness and creativity \& innovation.
\end{abstract}

\section{Introduction}

Creativity and innovation are essential factors in firms and organizational leaders because much of today's competitive marketplace demands substantial value to customers, which reduces different cost components, increase quality, cycle time, and overall customer satisfaction (Scott \& Bruce, 1994; Hunt et al., 2004). There are various studies on learning more about the effects of personality characteristics on creativity and innovation. Hoseinifar et al. (2011) performed an investigation on relationship between creativity and five factors of personality in high school students of Ardabil. They reported that boys were more creative than girls were. In addition, they showed that among five 
factors of personality, openness to experience, extraversion, agreeableness and conscientiousness were positive predictor of creativity and neurosis was negative predictor of creativity. Yesil and Sozbilir (2013) performed an empirical investigation into the effect of personality on individual innovation behavior in the workplace.

\section{The proposed study}

This paper examines the effects of big Five factors are openness, conscientiousness, extraversion, agreeableness, and neuroticism on creativity and innovation among selected employees of municipality in city of Tehran, Iran. The proposed study uses a standard questionnaire developed by Costa and McCrae (1980) and McCrae and Costa (1987) to measure the effects of five personality characteristics. In addition, the study has adopted a questionnaire developed by Torrents et al. (2010) for measuring creativity. The proposed model of this paper is as follows,

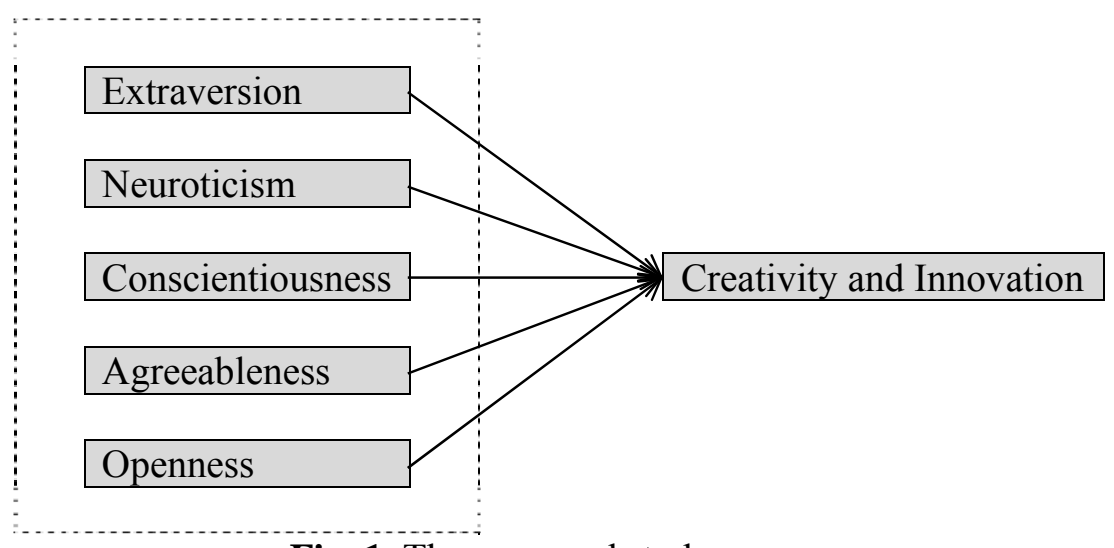

Fig. 1. The proposed study

The population of the study includes all full-time employees who work for municipality of Tehran, Iran. The sample size is calculated as follows,

$n=\frac{N \times z_{\alpha / 2}^{2} \times p \times q}{\varepsilon^{2} \times(N-1)+z_{\alpha / 2}^{2} \times p \times q}$,

where $N$ is the population size, $p=1-q$ represents the yes/no categories, $z_{\alpha / 2}$ is CDF of normal distribution and finally $\varepsilon$ is the error term. Since we have $p=0.5, z_{\alpha / 2}=1.96$ and $N=620$, the number of sample size is calculated as $n=237$. Cronbach alpha for openness, conscientiousness, extraversion, agreeableness, and neuroticism are $0.74,0.87,0.83,0.76$ and 0.86 , respectively. In addition, the creativity questionnaire consists of four factors including fluid, expansion, innovation and flexibility are $0.85,0.80,0.82$ and 0.84 , respectively. These values are well above the desirable limits and we therefore perform the survey among all randomly selected people. There are size hypotheses associated with the propsoed study of this paper as follows,

1. There is a positive and meaningful relationship between personality characteristics and creativity.

2. There is a negative and meaningful relationship between neuroticism and creativity and innovation.

3. There is a positive and meaningful relationship between extraversion and creativity and innovation.

4. There is a positive and meaningful relationship between openness and creativity and innovation. 
5. There is a positive and meaningful relationship between agreeableness and creativity and innovation.

6. There is a positive and meaningful relationship between conscientiousness and creativity and innovation.

Fig. 2 shows details of the personal characteristics of the participants.

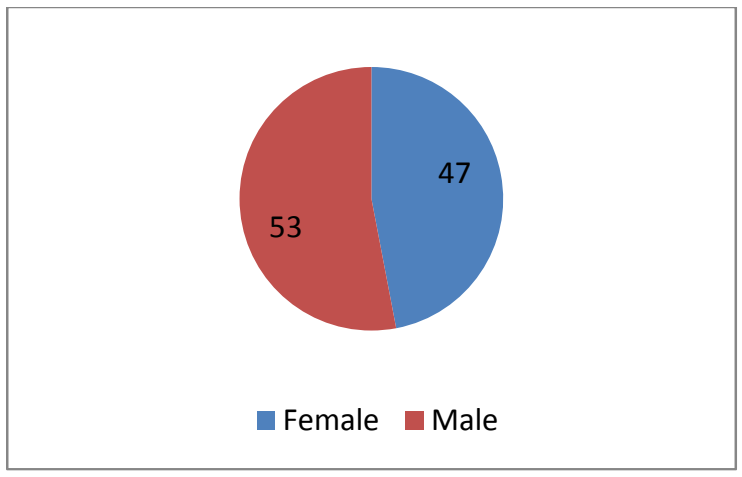

Gender

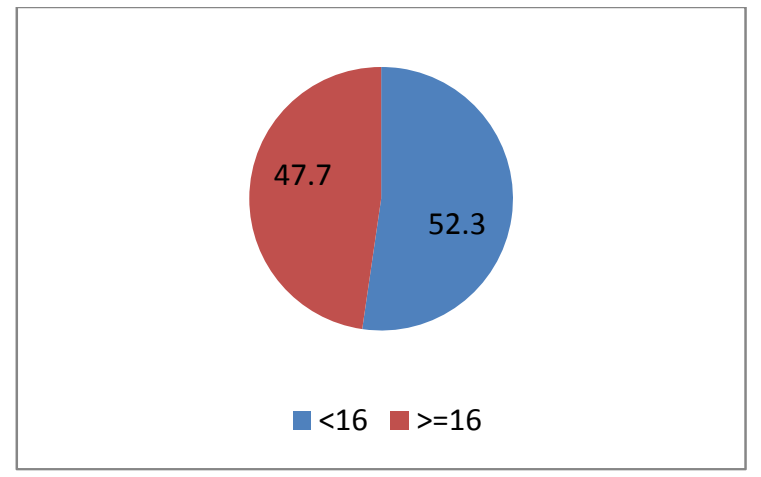

Years of education

Fig. 2. Personal characteristics of the participants

As we can observe from the results of Fig. 2, nearly half of the people who participated in our survey had at least a bachelor of science. The study uses Kolmogorov-Smirnov test to verify the normality of five big components of personality characteristics and Table 1 summarizes the findings of our survey.

\section{Table 1}

The summary of some basic statistics along with Kolmogorov-Smirnov

\begin{tabular}{lcccc}
\hline Component & No. & $Z$ & Sig. & Result \\
\hline Neuroticism & 237 & .680 & .745 & Confirmed \\
Extraversion & 237 & 1.175 & .127 & Confirmed \\
Openness & 237 & 1.235 & .095 & Confirmed \\
Agreeableness & 237 & .999 & .271 & Confirmed \\
Conscientiousness & 237 & .979 & .294 & Confirmed \\
Creativity \& Innovation & 237 & .585 & .883 & Confirmed \\
\hline
\end{tabular}

As we can observe from the results of Table 1, all components of the survey are normally distributed. The study uses regression analysis to examine different hypotheses of the survey. The general form of the proposed study is as follows,

CRE-INV $=\beta_{0}+\beta_{1}$ Big Five $+\varepsilon$,

where CRE-INV is the dependent variable, which represents creativity and innovation and Big Five states different components of personality characteristics including openness, conscientiousness, extraversion, agreeableness, and neuroticism.

\section{The results}

In this section, we present details of our findings on testing six hypotheses of the survey based on the implementation of structural equation modeling. Fig. 3 shows details of our findings. As we can observe from the results of Fig. 3, the coefficients associated with the first three variables including neuroticism, extraversion and openness are $-0.229,0.209$ and 0.225 , respectively and they are meaningful when the level of significance is five percent. However, the signs of two variables including agreeableness and conscientiousness are not statistically meaningful. 


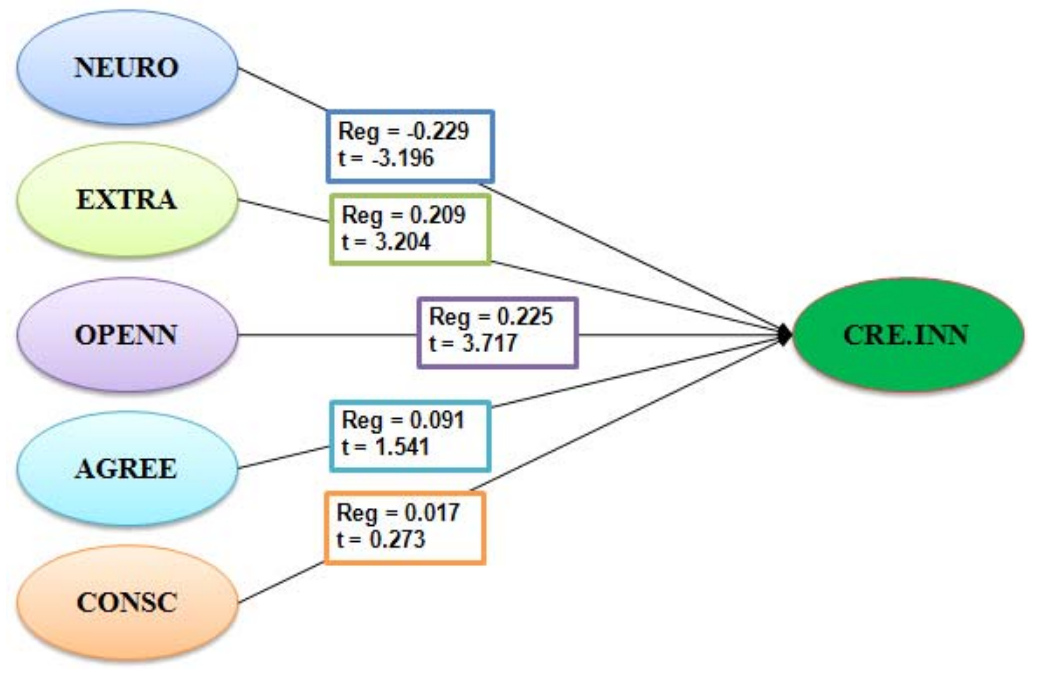

Fig. 3. The results of structural equation modeling

\section{Conclusion}

This paper has presented an empirical investigation to study the effects of five personality characteristics on creativity and innovation among regular employees of municipality of Tehran, Iran. Using a simple regression analysis, the study has detected negative and meaningful relationship between Neuroticism and creativity and innovation $(\beta=-0.229$, t-value $=-3.196)$, a positive and meaningful relationship between extraversion and creativity and innovation $(\beta=0.209$, t-value $=$ 3.204) and finally a positive and meaningful relationship between openness and creativity and innovation $(\beta=0.225$, t-value $=3.717)$. However, the study did not confirm on relationship between agreeableness as well as conscientiousness and creativity and innovation.

\section{Acknowledgement}

The authors would like to thank the anonymous referees for constructive comments on earlier version of this paper.

\section{References}

Costa, P. T., \& McCrae, R. R. (1980). Influence of extraversion and neuroticism on subjective wellbeing: happy and unhappy people. Journal of Personality and Social Psychology, 38(4), 668.

Hoseinifar, J., Siedkalan, M. M., Zirak, S. R., Nowrozi, M., Shaker, A., Meamar, E., \& Ghaderi, E. (2011). An investigation of the relation between creativity and five factors of personality in students. Procedia-Social and Behavioral Sciences, 30, 2037-2041.

Hunt, J. G. J., Stelluto, G. E., \& Hooijberg, R. (2004). Toward new-wave organization creativity: Beyond romance and analogy in the relationship between orchestra-conductor leadership and musician creativity. The Leadership Quarterly, 15(1), 145-162.

McCrae, R. R., \& Costa, P. T. (1987). Validation of the five-factor model of personality across instruments and observers. Journal of Personality and Social Psychology, 52(1), 81-90.

Scott, S. G., \& Bruce, R. A. (1994). Determinants of innovative behavior: A path model of individual innovation in the workplace. Academy of management journal, 37(3), 580-607.

Torrents, C., Castaner, M., DINUŠOVÁ, M., \& Anguera, M. T. (2010). Discovering new ways of moving: Observational analysis of motor creativity while dancing contact improvisation and the influence of the partner. The Journal of Creative Behavior, 44(1), 53-69.

Yesil, S., \& Sozbilir, F. (2013). An empirical investigation into the impact of personality on individual innovation behaviour in the workplace. Procedia-Social and Behavioral Sciences, 81, 540-551. 